\title{
Comparison of the Values of a Novel Exolytic and Two Endolytic Alginate Lyases with Mannuronate Preference for Direct Preparation of Oligosaccharides, Action Modes, and Underlying Catalytic Mechanisms
}

\author{
Lianghuan Zeng \\ Shandong University \\ Junge Li \\ Shandong University \\ Yuanyuan Cheng \\ Shandong Agriculture and Engineering University \\ Dandan Wang \\ Shandong University \\ Jingyan Gu \\ Jinan Enlighten Biotechnology Co. Itd \\ Wenjun Han ( $\nabla$ hanwenjun_79@sdu.edu.cn ) \\ Shandong University
}

\section{Research Article}

Keywords: Alginate lyase, Exolytic, Endolytic, Action modes, Oligosaccharide products

Posted Date: July 7th, 2021

DOl: https://doi.org/10.21203/rs.3.rs-664516/v1

License: (c) (i) This work is licensed under a Creative Commons Attribution 4.0 International License. Read Full License 


\section{Abstract}

Recent exploration of tool-like alginate lyases has focused on their oligosaccharide products and corresponding substrate action modes, and most were characterized as endolytic lyases with guluronate (G) preference. Herein, we elucidated a novel exolytic lyase, Aly-6, and two typical endolytic lyases, AlgLPae and AlgL-Avi, all with mannuronate (M) preferences. AlgL and heparinase_II_III modules play essential roles in determining the similar characteristics of these enzymes, although they are quite different in sequence characteristics. Aly- 6 degraded substrates completely by continuously cleaving various monosaccharide units from nonreducing ends and producing various size-defined $\Delta$ G-terminated oligosaccharide fractions as intermediate alginate digests, which was inhibited by fluorescent labeling of reducing ends. Distinctly, AlgL-Pae and AlgL-Avi varied their action modes toward associated alginate substrates and therefore eventually degraded alginate into various size-defined oligosaccharide products with a specific structure-based succession rule. This study provided new insights into the action modes, associated mechanisms, and enzyme applications of M-preferred lyases.

\section{Introduction}

Alginate is the most important polysaccharide component in the Phaeophyceae family of brown algae, which includes such genera as Ascophyllum, Laminaria, and Sargassum. Usually, alginate contributes approximately $40 \%$ of seaweed dry weights $(1)$. Alginate is composed of $\beta$ - $(1,4)$-linked uronic residues, i.e., $\beta$-D-mannuronate (M) and its C5-epimer a-L-guluronate (G), and thus forms in homogeneous fashion, i.e., poly-M and poly-G blocks, or a heterogeneous fashion, e.g., poly-MG and poly-GM blocks, within the linear molecule (2-4). Algal alginate, in particular G-enriched polysaccharides, is widely used in the food and pharmaceutical industries due to its excellent gel-forming capability and various associated beneficial effects (5-9). In contrast, alginate oligosaccharide products have been identified with important biological activities, e.g., antibacterial (10), antiobesity (11), antioxidation (12), and antiinflammatory effects (13), which are closely related to the molecular size (degree of poly-Merization, DP), the $\mathrm{M} / \mathrm{G}$ ratio, and the molecular modification type, e.g., acetylation or sulfation. In 2019 , a novel drug derived from oligo-mannuronate, GV-971 (14), was permitted for sale in China to treat Alzheimer's disease, which also means an economic value. Thus, direct preparation of sugar chains with designated sugar components and molecular sizes from alginate has urgently become a technical problem.

Compared to chemical and physical oligosaccharide preparation methods (15-18), enzymatic strategies have attracted attention for their environmental benefits and less-disordered and preserved sugar units at the chain ends (19-21). Alginate lyase can degrade alginate at the $\beta(1,4)$-glycoside linkages via $\beta$ elimination (22). In general, endolytic alginate lyases produce a series of size-defined oligosaccharide fractions as final alginate digests, with unsaturated units $(\Delta)$ at the newly formed nonreducing end (23$25)$; therefore, they are important for the preparation of various unsaturated oligosaccharide chains. Distinctly, throughout the alginate-degrading process, exolytic alginate lyases primarily yield the monosaccharide product of the $\Delta$ unit, which is further converted into 4-deoxy-L-erythro-5-hexoseulose uronate (DEH) under nonenzymatic conversion (25); thus, exolytic enzymes are essential for the 
bioconversion of alginate into biofuels. Hence, an increasing number of endolytic alginate lyases have been explored as resources and improved as enzymes with respect to their substrate preferences (M- or Gspecific, or bifunctional but preferring M or G), oligosaccharide products (e.g., the sizes of oligosaccharide products, the molar ratio of various product fractions, and the structure properties and inner changing rules), and corresponding substrate-degrading modes (e.g., the sizes of the smallest substrates and products, the yielding position of the smallest products, and the endolytic or exolytic patterns) (26), which are essential to clearly and exactly display the utility of enzymes in the direct preparation of targeting unsaturated oligoalginate chains.

For instance, the endolytic guluronate lyase Aly5 (27), a PL7 family member from the polysaccharidedegrading marine bacterium Flammeovirga sp. MY04 is valuable for producing unsaturated disaccharide products primarily consisting of $\Delta G$ units, unsaturated trisaccharide products containing $\Delta G$ in the presence of $\Delta M$ ends, and larger unsaturated products losing $\Delta G$ until only $\Delta M$ ends remain. Notably, the large size-defined final oligosaccharide products, e.g., UDP5, UDP6, and UDP7 fractions produced by rAly5, were identified as $\Delta \mathrm{M}$-ended and $\mathrm{M}$-enriched unsaturated sugar chains. Therefore, alginate degradation by Aly 5 can provide an alternative enzymatic preparation strategy to the chemical or physical strategies of preparing the novel drug GV-971. Two other PL7 family members, Aly1 (28) and Aly2 (29), which are bifunctional and G-preferred endolytic alginate lyases from the same MY04 strain, showed oligosaccharide products similar to those of Aly5, e.g., primarily disaccharide products of $\Delta G$ units, whereas for their bifunctional substrate preferences and greater enzyme activities, these two bifunctional enzymes yield only little large oligosaccharide fractions (> UDP4) in their final alginate digests. Hence, although these two G-preferred bifunctional alginate lyases are endolytic enzymes, they are thought invaluable for the preparation of large and bioactive unsaturated oligoalginates. Notably, although tens of alginate lyases have been reported with $\mathrm{G}$ specificity or $\mathrm{G}$ preference in recent decades, fewer than five endolytic enzymes have been well elucidated for oligosaccharide preparation purposes, which is an even lower proportion when compared to the larger number of reported alginate lyases with $M$ specificity or M preference. Therefore, we are interested in the utility and associated catalytic mechanisms of M-preferred lyases and the differences between endolytic and exolytic enzymes.

A number of bacterial strains of the Pseudomonas and Azotobacter genera can secrete extracellular alginate, which contains acetyl modification at the 0-2 or 0-3 positions of sugar rings (30-33) and are important components in drug-resistant bacterial biofilms. These bacteria encoded the periplasmic AlgL proteins of the PL 5 family by the gene algL localized within alginate biosynthesis operons. Through gene knockout and plasmid complementary tests of bacteria, these PL5 alginate lyases were identified to have essential roles in splicing large polysaccharide molecules into smaller molecules during alginate secretion. To date, seven AlgL module-containing proteins of the PL5 family have been reported to have crystal structures, key active site residues (e.g., the half-conserved NNHSYW motif), and associated functional roles in catalysis. Moreover, an increasing number of AlgL-conserved PL5 proteins have been widely identified by molecular mining of bacterial genomic data. However, relatively little is known about these enzymes' oligosaccharide products and corresponding substrate action modes, except for their Mspecificities or preferences, which urgently needs to be overcome for direct preparation, structure 
identification, and functional explorations of novel unsaturated oligosaccharide chains by the use of these alginate lyases.

In this study, the wild-type genes of AlgL-Pae and AlgL-Avi were initially codon-optimized, artificially synthesized, and then cloned and expressed in Escherichia coli strain BL21(DE3) for comparison to the wild-type Aly-6 gene of Flammeovirga sp. strain MY04. The resulting recombinant proteins were individually purified for comparative studies on their biochemical characteristics, enzymatic properties (substrate preference, substrate-degrading modes, and the resulting oligosaccharide products), and particularly their structural relationships. Furthermore, gene truncations and site-directed mutations were performed using rational design of homology-based protein structure modeling to determine the enzymatic function changes and associated catalytic mechanisms.

\section{Materials And Methods}

\subsection{Bacterial strains, carbohydrates, and growth conditions.}

Cells of Escherichia coli strains, i.e., DH5a or BL21(DE3), were cultured at $37^{\circ} \mathrm{C}$ for gene cloning and at $16^{\circ} \mathrm{C}$ for protein expression in Luria-Bertani (LB) broth that was supplemented with ampicillin to a final concentration of $100 \mu \mathrm{g} / \mathrm{ml}$ or with kanamycin at $50 \mu \mathrm{g} / \mathrm{ml}$ when necessary. Flammeovirga sp. strain MY04 (CGMCC No. 2777) was cultured at $30^{\circ} \mathrm{C}$ in a medium (pH 7.0) comprising (w/v) $0.40 \%$ tryptone, $0.25 \%$ yeast extract, and $3.0 \% \mathrm{NaCl}(34)$. Solid medium plates were prepared by supplementing additional agar powder $(1.5 \%, \mathrm{w} / \mathrm{v})$.

Agarose, alginate (viscosity: $\geq 2,000 \mathrm{cP}, 2 \%\left(25^{\circ} \mathrm{C}\right)$ ), chondroitin, chondroitin sulfates $(\mathrm{A}, \mathrm{C}, \mathrm{D}$, and $\mathrm{E}$ types), hyaluronan, heparin, heparin sulfate, pectin, and xanthan were purchased from Sigma-Aldrich Co. Ltd., USA. Acetylated alginate fractions were purchased from Biosynth Carbosynth Co. Ltd., China. Poly-G blocks, poly-M blocks, and standard size-defined G-enriched or M-enriched saturated sugar chains (ranging from disaccharide to heptosaccharide in size, with $>95 \%$ promised purities) were purchased from Qingdao Biozhi Biotech Co. Ltd, China. Various size-defined unsaturated oligosaccharide fractions were prepared using the alginate lyases rAly5 and rAly1 as described in previous studies (27-28) or using recombinant alginate lyases rAly-6, Pae-rAlgL, and Avi-rAlgL in this study.

\subsection{Gene and protein sequences.}

The DNA sequence of ORF2549 from the genome of Flammeovirga sp. strain MY04 was translated into the amino acid sequence of the Aly- 6 protein, and the $\mathrm{GC}$ content $(\mathrm{G}+\mathrm{C} \%)$ was calculated using BioEdit version 7.2.5. Signal peptides were analyzed using SignalP server 5.0 (http://www.cbs.dtu.dk/services/). Molecular weights and the isoelectric point (pl) of the protein were estimated using the peptide mass tool on the ExPASy server of the Swiss Institute of Bioinformatics (http://swissmodel.expasy.org/). Online similarity searches of the Aly- 6 protein sequence were performed using the BLAST algorithm on the National Center for Biotechnology Information server (http://www.ncbi.nlm.nih.gov). Protein modules and domains were identified using the Simple Modular Architecture Research Tool 
(https://en.wikipedia.org/wiki/Simple_Modular_Architecture_Research_Tool), the Pfam database (http://pfam.xfam.org), and the Carbohydrate-Active Enzyme database (http://www.cazy.org). Multiple sequence alignments and phylogenetic analyses were performed using MEGA version 7.2.5 (35). Two wild-type DNA sequences that encode the periplasmic AlgL proteins of $P$. aeruginosa (under the GenBank nucleotide No. U27829.1/Protein No. AAA91127.1) and A. vinelandii (Nucleotide No. AF027499/Protein No. AAC04567.1) were analyzed as described above.

\subsection{Construction of expression vectors.}

Genomic DNA of the Flammeovirga sp. strain MY04 was prepared and purified using the FastPure bacterial DNA isolation mini kit (Vazyme Biotech Co. Ltd., Nanjing, China). To express the whole Aly-6 protein, the full-length gene was amplified from genomic DNA using high fidelity Vazyme ${ }^{\text {TM }}$ LAmp DNA poly-Merase (Vazyme Biotech Co. Ltd., Nanjing, China) and the primers TF-Aly-6-F (5'ggCATATGCAGAACGGAAATTTAATTACTTCCG-3') and TF-Aly-6-R (5'-

gCTCTAGAAATTTCTTCCAATAGGTAAACCCC-3'), which were designed for use with the restriction enzymes (sites underlined) Nde I and Xba I in the plasmid pCold TF (TaKaRa, Dalian, China) to fuse a $6 \times$ His tag and a TF-factor in sequence at the $\mathrm{N}$-terminus of the recombinant protein. The PCR product was finally enzyme-cloned into the expression vector pCold TF, producing the recombinant plasmid pCTFAly- 6 to yield the rCTF-Aly- 6 protein. To express the His $\times 6$-tagged and TF-factor-fused soluble protein of the putative $N$-terminal module (AlgL module) of Aly-6, i.e., the recombinant protein rTF-Aly-6-L module, the primers TF-Aly-6-Lm-F (5'-ggCATATGCAGAACGGAAATTTAATTACTTCCGAG-3', Ndel) and TF-Aly-6-LmR (5'-gcTCTAGACAAACTTCTTTTTTGGTAAGTC GTTGC-3', Xba I) were designed and used in the construction of the recombinant plasmid pCTF-Aly-6-L. For expression of the $6 \times$ His-tagged and TF-factorfused soluble protein of the putative $C$-terminal module (heparinase II or III module) of Aly-6, i.e., the recombinant protein of the rTF-Aly-6-HP module, the primers TF-Aly-6-Hpm-F (5'-

ggCATATGTACTATTCAAGAGAATTGAAACTAGCC-3', Nde I) and TF-Aly-6-Hpm-R (5'-

gCTCTAGAAATTTCTTCCAATAGGTAAACCCC-3', Xba I) were designed and used for the construction of the recombinant plasmid pCTF-Aly-6-HP. The recombinant plasmids pCTF-Aly- 6 and pET-30a (+) were double digested with restriction enzymes $\mathrm{NdeI}$ and $\mathrm{Xba}$, and the digested fragments were recovered by gel electrophoresis and then ligated by NDA ligase, yielding the recombinant plasmid pE30-Aly- 6 to produce the full-length rAly-6 protein.

The wild-type genes of AlgL-Pae and AlgL-Avi were optimized for G + C content and nucleotide codons, artificially synthesized, and finally directly cloned into the plasmid vector pET-30a (+) between $\mathrm{NdeI}$ and Xho I restriction sites, thus forming the recombinant plasmids pE30-AlgL-Pae and pE30-AlgL-Avi to produce the recombinant proteins Pae-rAlgL and Avi-rAlgL, respectively. Markedly, the resulting proteins included no signal peptide at the $N$-terminus but rather a $6 \times \mathrm{His}$ tag at the newly formed $C$-terminus. The integrity of the nucleotide sequences of newly constructed plasmids was confirmed by DNA sequencing.

\subsection{Heterologous expression and purification of recombinant proteins.}


Recombinant proteins were expressed and purified using the same procedures described for the recombinant alginate lyase rAly5 of Flammeovirga sp. strain MY04 (27). Briefly, each recombinant plasmid was transformed into E. coli BL21(DE3) cells. To initiate protein expression, LB broth was supplemented with isopropyl 1-thio- $\beta$-D-galactoside to a final concentration of $0.05 \mathrm{mM}$ when the $A_{600}$ reached 0.8 . After a continual $24 \mathrm{~h}$ cultivation at $16^{\circ} \mathrm{C}$, cells were harvested by centrifugation at $6,000 \times g$ for $10 \mathrm{~min}$, washed twice using ice-cold buffer $\mathrm{A}$ ( $50 \mathrm{mM}$ Tris, $150 \mathrm{mM} \mathrm{NaCl}, \mathrm{pH} 8.0$ ), resuspended in buffer $A$, and disrupted by sonication (60 repetitions, $5 \mathrm{~s}$ ). After centrifugation at $15,000 \times g$ for $30 \mathrm{~min}$, the supernatant containing each soluble protein was loaded onto a buffer A-equilibrated Ni-nitrilotriacetic acid agarose (Ni-NTA) column (TaKaRa, Dalian, China). Subsequently, each column was eluted using buffer $A$ that contained imidazole in increasing concentrations, specifically, $0,10,50$, and $250 \mathrm{mM}$. Fractionated protein samples were analyzed using SDS-PAGE. To obtain active alginate lyases, purified protein fractions were dialyzed against buffer $\mathrm{B}(50 \mathrm{mM}$ Tris, $50 \mathrm{mM} \mathrm{NaCl}, 5 \%$ glycerol $(\mathrm{v} / \mathrm{v}), \mathrm{pH} 8.0)$.

SDS-PAGE was performed using $13.2 \%(\mathrm{w} / \mathrm{v})$ polyacrylamide gels according to the methods of Sambrook and Russell (36). Proteins were detected by staining the gels with Coomassie Brilliant Blue R-250. Protein concentrations were individually determined by the Folin-Lowry method using Folin and Ciocalteu's phenol reagent (Sigma-Aldrich, USA) with bovine serum albumin as the standard.

\subsection{Enzyme activity assays.}

To determine the substrate preference of each purified recombinant protein, various polysaccharides and oligosaccharides were individually dissolved in deionized water to prepare stock solutions $(3 \mathrm{mg} / \mathrm{ml})$. Each stock solution $(100 \mu \mathrm{l})$ was mixed with $30 \mu \mathrm{l}$ of appropriately diluted enzyme preparation, $100 \mu \mathrm{l}$ of $150 \mathrm{mM} \mathrm{NaAc}-\mathrm{HAc}$ buffer ( $\mathrm{pH} 6.0)$, and $70 \mu \mathrm{l}$ of water. Each reaction was performed at $40^{\circ} \mathrm{C}$ for $12 \mathrm{~h}$. Enzyme-treated samples were heated in boiling water for $10 \mathrm{~min}$ and subsequently ice-cooled. After centrifugation at $15,000 \times \mathrm{g}$ for $15 \mathrm{~min}$, the supernatant was collected and analyzed by measuring the absorbance at $235 \mathrm{~nm}$. One unit was defined as the amount of enzyme required to increase the absorbance at $235 \mathrm{~nm}$ by 0.1 per $\min (23)$, and samples $(1.0 \mathrm{mg} / \mathrm{ml})$ were analyzed by gel filtration on a Superdex peptide 10/300 GL column (GE Healthcare, USA) and had their absorbance monitored at 235 $\mathrm{nm}$ using a UV detector. The mobile phase was $0.2 \mathrm{M} \mathrm{NH}_{4} \mathrm{HCO}_{3}$, and the flow rate was $0.4 \mathrm{ml} / \mathrm{min}$. Online monitoring and data analysis were performed using LCsolution version 1.25 software.

\subsection{Biochemical characterization of recombinant proteins.}

To determine the optimal temperature for alginate lyase activities, alginate, poly-G blocks, and poly-M blocks were individually reacted with the protein preparations. Enzymatic reactions were performed in 50 $\mathrm{mM} \mathrm{NaAc-HAc}$ buffer ( $\mathrm{pH} \mathrm{6.0)}$ ) at temperatures ranging from 0 to $80^{\circ} \mathrm{C}$ for $90 \mathrm{~min}$. After the optimal temperature was determined, the effects of $\mathrm{pH}$ on enzyme activity were tested in different buffers, including $50 \mathrm{mM} \mathrm{NaAc}-\mathrm{HAc}$ buffer (pH 5.0, and 6.0), $50 \mathrm{mM} \mathrm{NaH}_{2} \mathrm{PO}_{4}-\mathrm{Na}_{2} \mathrm{HPO}_{4}$ buffer (pH 6.0, 7.0, and 8.0), and $50 \mathrm{mM}$ Tris-HCl buffer (pH 7.0, 8.0, 9.0, and 10), each with a total volume of $300 \mu \mathrm{l}$. The thermostability was evaluated by measuring the residual enzyme activity of each enzyme preparation after incubation for 0 to $24 \mathrm{~h}$ at 0 to $80^{\circ} \mathrm{C}$. The effects of $\mathrm{pH}$ on enzyme stability were determined by 
measuring the residual activity of each enzyme after incubation at $4^{\circ} \mathrm{C}$ at varying $\mathrm{pH}$ values $(5.0-10)$ for $2 \mathrm{~h}$. The effects of metal ions and chelating agents on alginate lyase activities were examined by determining the activity of each enzyme in the presence of $1 \mathrm{mM}$ metal ion or $10 \mathrm{mM}$ chelating agent. The effects of $\mathrm{NaCl}$ on alginate lyase activities were examined by determining the activity of each enzyme in different concentration $(0.0$ to $1.0 \mathrm{M})$. All reactions were performed in triplicate. After each treatment, the enzyme activity was estimated by measuring the absorbance at $235 \mathrm{~nm}$ as described previously in 2.5 .

\subsection{Comparison of polysaccharide-degrading patterns.}

To compare the polysaccharide degradation patterns of the recombinant proteins, alginate $(1.0 \mathrm{mg} / \mathrm{ml})$ digestion by each enzyme $(1.0 \mathrm{U} / \mathrm{ml})$ at $40^{\circ} \mathrm{C}$ was traced over $72 \mathrm{~h}$. Similar experiments were performed at alginate concentrations ranging from $1.0 \mathrm{mg} / \mathrm{ml}$ to $10 \mathrm{mg} / \mathrm{ml}$. Aliquots of the digests were removed for time-course analysis. To determine the molar ratios of oligosaccharide fractions in the products, samples $(1.0 \mathrm{mg} / \mathrm{ml})$ were analyzed as described in 2.5 .

To determine the oligosaccharide compositions of the final alginate degradation products, $100 \mathrm{mg}$ of alginate $(1.0 \mathrm{mg} / \mathrm{ml})$ was initially digested by an excess of each recombinant enzyme $(10 \mathrm{U} / \mathrm{ml})$ at $40^{\circ} \mathrm{C}$ and $\mathrm{pH} 6.0$ for more than $72 \mathrm{~h}$. Moreover, similar operations were performed for rAly- 6 and rTF-Aly- 6 at pH 7.0 to obtain intermediate alginate digests. To further obtain each size-defined unsaturated oligosaccharide product fraction, the final alginate degradation products of Pae-rAlgL and Avi-rAlgL or the intermediated alginate digests by rAly- 6 and rTF-Aly- 6 were individually gel-filtered through a Superdex peptide 10/300 GL column using the same protocol as described in 2.5. Each fraction was collected and freeze-dried repeatedly to remove $\mathrm{NH}_{4} \mathrm{HCO}_{3}$ for further analysis. The molecular mass of each oligosaccharide fraction was determined by matrix-assisted laser desorption/ionization time-of-flight mass spectrometry (AXIMA-CFR plus, Shimadzu, Japan). For ${ }^{1} \mathrm{H}$-NMR spectroscopy, each purified oligosaccharide fraction ( $2 \mathrm{mg}$ ) was dissolved in $0.3 \mathrm{ml}$ of $\mathrm{D}_{2} \mathrm{O}$ in $5-\mathrm{mm}$ NMR tubes. The spectra were recorded on a JNM-ECP600 (JEOL, Japan) apparatus set at $600 \mathrm{MHz}$ using TMS as the internal standard.

\subsection{Comparison of oligosaccharide degradation patterns.}

To determine the smallest substrate for each recombinant enzyme, unsaturated oligosaccharides with different degrees of poly-Merization (DPs), e.g., UDP2, UDP3, UDP4, UDP5, UDP6, and UDP7 fractions, were first purified from the final alginate digests by various endolytic alginate lyases, specifically rAly 1 (bifunctional but G-preferred) and rAly5 (G-specific) of Flammeovirga sp. strain MY04. In addition, unsaturated oligosaccharide fractions were also purified from alginate that had been completely digested by the recombinant enzymes Pae-rAlgL and Avi-rAlgL or alginate that had been partially digested by the recombinant enzymes rAly-6 or rTF-Aly- 6 as described in 2.7. Then, the obtained oligosaccharide fractions were used as substrates for each recombinant enzyme preparation. To further determine the substrate preference and oligosaccharide degradation patterns of each enzyme, saturated standard sizedefined M-enriched and G-enriched sugar chains were individually reacted with the recombinant enzyme 
preparations. The tested natural substrates and their enzymatic products $(20 \mu \mathrm{g}$ each) were subjected to the gel filtration assay described in 2.5 .

To fully compare the enzymatic degradation patterns of each recombinant enzyme preparation, various size-defined saturated and unsaturated oligosaccharide fractions were fluorescently labeled at their reducing ends using excess 2-aminobenzamide (2-AB, Sigma-Aldrich, USA) (37). The artificially labeled products $(\sim 1 \mu \mathrm{g}$ each) were purified by gel-filtration HPLC and further reacted with each enzyme $(5 \mathrm{U})$ in a total volume of $1 \mathrm{ml}$ using the protocol described in 2.7. The above artificial substrates and their enzymatic products (50 ng each) were subjected to the gel filtration assay described in 2.5 and monitored with a fluorescence detector and excitation and emission wavelengths of 330 and $420 \mathrm{~nm}$, respectively.

\subsection{Analysis of the catalytic mechanism of the recombinant proteins.}

SWISS-MODEL software (http://swissmodel.expasy.org/) was used for homology modeling. Then, the three-dimensional structure of Aly- 6 was analyzed, and the active site residues of the protein were predicted by PyMOL (http://pymol.org/). Using mutant primers (Table. S1) for reverse PCR with the recombinant plasmid (pET30a-Aly-6) as a template, the correct mutant recombinant plasmids were obtained and named pET30a-Aly-6-N144A, pET30a-Aly-6-H197A, pET30a-Aly-6-W200A, pET30a-Aly-6Y269A, pET30a-Aly-6-H426A, and pET30a-Aly-6-T-G224-A248. The methods of recombinant plasmid construction, expression, and enzyme activity analysis are described in Sect. 2.3, 2.4, and 2.5, respectively.

\section{Results}

\subsection{Sequence characteristics of the alginate lyases.}

ORF2549 in the genome of Flammeovirga sp. strain MY04 was predicted to encode a candidate polysaccharide lyase, Aly-6 (GenBank Protein Accession No. ANQ49918.2). The gene is 2,238 bp in fulllength with a GC content of $36.8 \%$. The putative protein Aly- 6 is composed of 745 amino acid residues with an apparent molecular mass of $84.67 \mathrm{kDa}$. The predicted pl value is 7.30 . SignalP 5.0 analysis indicated that the signal peptide of Aly-6 contains 23 amino acid residues (Met ${ }^{1}$ to Ser ${ }^{23}$ ) (Fig. 1C).

Analyses using the Carbohydrate-Active Enzyme database and the Simple Modular Architecture Research Tool indicated that the Aly- 6 protein contains a putative $\mathrm{N}$-terminal catalytic module ( $\mathrm{Ala}^{76}$ to $\mathrm{Phe}^{320}$ ) associated with PL5 alginate lyases (AlgL), as well as a putative $C$-terminal module ( Leu $^{391}$ to Val ${ }^{664}$ ) associated with heparinase II or III (Hep II_III) from Pedobacter heparinus (Fig. 1C). BLASTp searches showed that among characterized enzymes, the whole Aly- 6 protein shares the greatest sequence identity (38.93\%) with the exo-type alginate lyase Alg17c from Saccharophagus degradans strain 2-40, followed by 38-35\% identities with four other reported PL17 family alginate lyases (Fig. 1D): OalS17 of Shewanella sp. strain Kz7, AlgL of Sphingomonas sp. strain MJ-3, OAL of Stenotrophomonas maltophilia, and Alyll of Pseudomonas sp. strain OS-ALG-9. Subsequently, the full-length Aly-6 protein shares very low 
sequence identities with PL15 and PL5 family alginate lyases (Table. S2). The PL17 proteins described above are all organized in an AlgL and Hep_II_III complex modular architecture similar to that of Aly-6. Notably, the whole Aly-6 protein shares no homology with studied PL6 or PL7 alginate lyases, including Aly1, Aly2, and Aly5 from the same Flammeovirga strain MY04, which contains neither AlgL-like nor Hep_IIIIII-like modules.

Furthermore, protein sequence alignment showed that the AlgL module of Aly- 6 contains one putative catalytic motif, $\mathrm{H}^{195}-\mathrm{N}^{196}-\mathrm{H}^{197}-\mathrm{S}^{198}-\mathrm{T}^{199}-\mathrm{W}^{200}$, which is half-conserved but different from the conserved NNHSYW catalytic motif of diverse PL5 alginate lyases and the conserved HNHG(A)TW catalytic motif of various PL17 alginate lyases (Fig. S1). Phylogenetic analysis indicated that Aly-6, together with the six genome-predicted alginate lyases that are organized in the same AlgL and Hep_II_III complex modular architecture, i.e., four proteins of other Flammeovirga strains, one of Roseivirga ehrenbergii, and one of $R$. echinicomitans, are clustered into a novel separate branch within the PL17 superfamily (Fig. 1D).

\subsection{Production and purification of the full-length and truncated recombinant proteins.}

The full-length Aly- 6 gene was amplified directly from the genomic DNA of Flammeovirga sp. strain MY04. The 2.3-kb PCR products produced by the primers E30Aly-6-F and E30Aly-6-R were gel-recovered and enzyme-cloned into the pET30a (+) vector downstream of a T7 promoter. Thus, a His 66 tag was successfully added to the $C$-terminus of the protein product (rAly-6) encoded by the resulting expression vector (pET30-Aly-6). Similar operations were performed on the PCR products produced by three primer pairs, TF-Aly-6-F and TF-Aly-6-R, TF-Aly-6-Lm-F and TF-Aly-6-Lm-R, and TF-Aly-6-Hpm-F andTF-Aly-6-HpmF, to obtain the expression vectors pCTF-Aly-6, pCTF-Aly-6-Lmodule, and pCTF-Aly-6-HPmodule, which added a His $\times 6$ tag followed by a TF factor to the $N$-terminus of the full-length protein product (rTF-Aly- 6 ) and two truncated protein products (rTF-Aly-6-Lmodule and rTF-Aly-6-Hpmodule) individually, thus generating recombinant fusion proteins. To express and purify the recombinant proteins Pae-rAlgL and Avi-rAlgL, similar operations were performed using the pET30a (+)-derived recombinant vectors $\mathrm{pE30}$ AlgL-Pae and pE30-AlgL-Avi, which added a His $\times 6$ tag at the $C$-terminus of the AlgL-Pae and AlgL-Avi proteins, respectively.

SDS-PAGE analyses indicated that BL21(DE3) cells harboring each of the above recombinant plasmids produced soluble proteins (Fig. S2), with the correct apparent molecular mass and yields greater than 1.0 $\mathrm{g} /$ liter. After sonication and centrifugation, crude enzymes were each extracted from the $E$. coli cultures. The soluble protein fractions containing rAly-6, rTF-Aly-6, rTF-Aly-6-Lmodule, rTF-Aly-6-Hpmodule, PaerAlgL, and Avi-rAlgL were eluted from a Ni-nitrilotriacetic acid (NTA) column using imidazole at concentrations above $50 \mathrm{mM}$. Further SDS-PAGE analyses indicated that the purified soluble proteins each had purities greater than $99 \%$ and initial concentrations greater than $1.0 \mathrm{mg} / \mathrm{ml}$ (Fig. S2).

\subsection{Enzyme characteristics of the recombinant proteins.}


The recombinant proteins rAly- 6 and rTF-Aly- 6 showed the same substrate spectrum, i.e., they did not digest chondroitin, chondroitin sulfates (A, C, D, and E types), dermatan sulfate B, hyaluronan, heparin, heparin sulfate, pectin, or xanthan, but they efficiently digested alginate, $\mathrm{M}$ blocks, and $\mathrm{G}$ blocks to produce oligosaccharide products exhibiting strong absorbance at $235 \mathrm{~nm}$. The results suggested that the Aly- 6 protein of Flammeovirga sp. strain MY04 is a bifunctional alginate lyase. Furthermore, enzyme activity tests of rAly- 6 and rTF-Aly- 6 indicated a similar substrate preference for M over G (Table. 1). Quite different from the whole proteins rAly- 6 or rTF-Aly- 6 , the recombinant soluble truncated Aly- 6 proteins, i.e., rTF-Aly-6-Lmodule and rTF-Aly-6-HPmodule, showed little degradation activity against any tested polysaccharides, including alginate-associated substrates (Table. 1), indicating that both the AlgL-like and the Hep_II_III-like modules are integral for the alginate lyase activity of the whole Aly- 6 enzyme of Flammeovirga sp. strain MY04. Furthermore, the above results demonstrated that in the Aly- 6 protein, the Hep_II_III-like module is only a putative element instead of a catalytic module against any tested glycoaminoglycans, including heparin or heparin sulfates. The purified protein fractions of Pae-rAlgL and Avi-rAlgL could efficiently degrade only alginate and $\mathrm{M}$ blocks to generate unsaturated oligosaccharide products, and they could hardly digest any other tested polysaccharides, including G blocks (Table. 1), demonstrating that they are M-specific lyases, as reported previously. In addition, none of the above protein preparations degraded acylated alginate from Azotobacter or Pseudomonas bacterial strains to produce detectable oligosaccharide products.

The whole enzyme rAly- 6 demonstrated the highest activity at $40^{\circ} \mathrm{C}$ when alginate, M-enriched blocks, or G-enriched blocks were used as substrates (Fig. S3A). A thermostability assay further showed that the alginate-degrading activity of rAly- 6 was stable at 0 to $30^{\circ} \mathrm{C}$, and more than $60 \%$ activity was retained even if the enzyme was preincubated at $30^{\circ} \mathrm{C}$ for $24 \mathrm{~h}$ (Fig. S3C). The optimal $\mathrm{pH}$, determined at $40^{\circ} \mathrm{C}$ in both $50 \mathrm{mM}$ sodium acetate-acetic acid (NaAc-HAc) buffer and $50 \mathrm{mM} \mathrm{NaH} \mathrm{PO}_{4}-\mathrm{Na}_{2} \mathrm{HPO}_{4}$ buffer, was 6.0 (Fig. S3B). The enzyme retained more than $60 \%$ of the highest activity after preincubation for $2 \mathrm{~h}$ at pH 5.0 to 8.0 (Fig. S3B). The TF-factor-fused recombinant enzyme rTF-Aly-6 showed similar biochemical characteristics, i.e., the optimal temperature and $\mathrm{pH}$ value for catalysis and the enzyme's thermal and $\mathrm{pH}$ stabilities, to rAly-6.

The alginate lyase activities of rAly- 6 were strongly inhibited by 1.0 or $10 \mathrm{mM} \mathrm{Ag}^{+}, \mathrm{Cu}^{2+}, \mathrm{Hg}^{2+}$, sodium dodecyl sulfonate (SDS), $10 \mathrm{mM} \mathrm{Pb}^{2+}, \mathrm{Zn}^{2+}, \mathrm{Cr}^{3+}, \mathrm{Fe}^{3+}$, or ethylenediaminetetraacetic acid (EDTA). In contrast, the enzyme activity of rAly- 6 was increased to $130 \sim 160 \%$ by various concentrations (1.0 or 10 $\mathrm{mM}$ ) of $\mathrm{Co}^{2+}, \mathrm{Mn}^{2+}$, and $\mathrm{Ni}^{2+}$. Chemicals such as glycerol, dithiothreitol (DTT), and the reducing agent $\beta$ mercaptoethanol ( $\beta-\mathrm{ME})$ weakly increased the activity of Aly-6 (Fig. S3E). Moreover, the enzyme activity of rAly- 6 was strongly increased by increasing the $\mathrm{NaCl}$ concentration from 0.0 to $0.5 \mathrm{M}$, reaching approximately $210 \%$ at $0.2 \mathrm{M}$, whereas it was strongly inhibited by increasing the $\mathrm{NaCl}$ concentration from 0.5 to $1.0 \mathrm{M}$, decreasing to approximately $10 \%$ at $1.0 \mathrm{M}$ (Fig. S3D). The results indicated that the alginate lyase Aly- 6 is active without $\mathrm{NaCl}$ while being adapted to a range of $\mathrm{NaCl}$ concentrations, which may be associated with the protein origin, Flammeovirga sp. strain MY04, being derived from coastal environments. Similar to that of rAly-6, the enzyme activities of Avi-rAlgL and Pae-rAlgL were both 
strongly inhibited by 1.0 or $10 \mathrm{mM}$ SDS or $10 \mathrm{mM} \mathrm{Cu}^{2+}, \mathrm{Hg}^{2+}, \mathrm{Pb}^{2+}, \mathrm{Zn}^{2+}, \mathrm{Cr}^{3+}$, or Fe ${ }^{3+}$ (Fig. S4A and B). Moreover, their enzyme activities were $\mathrm{NaCl}$ independent and increased by increasing the $\mathrm{NaCl}$ concentration from 0 to $1.0 \mathrm{M}$, reaching approximately $130 \%$ at over $0.2 \mathrm{M} \mathrm{NaCl}$, while Avi-rAlgL activity reached $160 \%$ at $0.6 \mathrm{M}$ (Fig. S4C and D).

Under optimal conditions ( $40^{\circ} \mathrm{C}$ in $50 \mathrm{mM} \mathrm{NaAc}-\mathrm{HAc}$ buffer, $\mathrm{pH}$ 6.0), the enzyme rAly- 6 showed specific activities of $726 \pm 2.2,525 \pm 3.5,196 \pm 2.9 \mathrm{U} / \mathrm{mg}$ in the degradation of alginate, $\mathrm{M}$ blocks, and $\mathrm{G}$ blocks. These results demonstrated that the enzyme activity of Aly- 6 against $M$ blocks is almost 2.71-fold that against $\mathrm{G}$ blocks, and therefore Aly- 6 is an M-preferred lyase. Similarly, the reported M-specific lyases PaerAlgL and Avi-rAlgL exhibited activities of 2685/4219, 5704/8085, and 144/98 U/mg in the degradation of the corresponding substrates (Table. 1), respectively.

\subsection{Polysaccharide degradation patterns and oligosaccharide products.}

Unsaturated oligosaccharides with a high degree of poly-Merization (DP) were the main products in the initial stage of the reaction and were then gradually converted into smaller oligosaccharides (Fig. S5A and $B$ ), indicating that Avi-rAlgL and Pae-rAlgL are typical endo-type alginate lyases. The final products were similar (UDP2 UDP7) but with differing molar ratios for each component (Fig. S5D). These enzymes also degrade unsaturated oligosaccharides endolytically. Unlike the two endolytic agents, rAly- 6 exhibited a different degradation behavior (Fig. S5C). To further identify the structures of oligosaccharides produced by rAly-6, Avi-rAlgL, and Pae-rAlgL, six size-defined oligosaccharide fractions, UDP2 UDP7 (Avi-rAlgL and Pae-rAlgL), were isolated from the final products, and UDP3 UDP6 (rAly-6) were isolated from intermediate products of alginate digestion as described above. The ${ }^{1} \mathrm{H}-\mathrm{NMR}$ chemical shifts of the protons of the $\Delta$ unit at the nonreducing end of unsaturated alginate oligosaccharides are strongly affected by the properties of the nearest monosaccharide residues and the structure of the residue next to the $\Delta$ unit $(29,38-40)$. In the case of UDP3 $\sim$ UDP6 produced by rAly-6, the specific signal at $5.65 \mathrm{ppm}$ of $\mathrm{H}-4$ of $\Delta \mathrm{G}$ was strong, but no $\mathrm{H}-4$ of $\Delta \mathrm{M}$ was observed, indicating that rAly-6 (Fig. $2 \mathrm{C}$ ) is currently the first alginate lyase that produced $\Delta \mathrm{G}$-terminal oligosaccharide products.

In addition, the UDP2 UDP7 products from Avi-rAlgL and Pae-rAlgL were also analyzed. The observed characteristic chemical shift value indicated that almost all the UDP2 (5.65 ppm) produced by Avi-rAlgL and Pae-rAlgL was $\triangle \mathrm{M}$, while the UDP5 UDP7 fractions produced by Pae-rAlgL and UDP4 UDP7 produced by Avi-rAlgL (5.70 ppm) were $\Delta \mathrm{G}$ (Fig. $2 \mathrm{~A}$ and $\mathrm{B}$ ). The signals at $5.70 \mathrm{ppm}$ and $5.60 \mathrm{ppm}$ of UDP3 (Avi-rAlgL and Pae-rAlgL) and UDP4 (Pae-rAlgL), respectively, showed that UDP3 was $\triangle \mathrm{M}$ and UDP4 was $\triangle G$, with molar ratios of 100:104, 134:100, and 100:196. In short, the products produced by Avi-rAlgL and Pae-rAlgL during alginate degradation are similar, and the difference is that only UDP3 produced by Avi-rAlgL, not UDP3 and UDP4 from Avi-rAlgL, has two types of nonreducing ends, $\triangle \mathrm{M}$ and $\Delta G$. Therefore, although the characteristic succession of the $n r$ end structure of the oligosaccharide end products of the two endo-type alginate lyases is that as the degree of poly-Merization increases, the proportion of nonreducing-end-containing $\Delta \mathrm{M}$ of the oligosaccharide gradually decreases and the $\Delta \mathrm{G}$ 
gradually increases to completely replace $\Delta \mathrm{M}$, these two enzymes preferred to produce large oligosaccharides (> UDP5) in which the $n r$ end primarily contained $\Delta \mathrm{G}$ units.

To investigate the oligosaccharide-degrading properties of the three alginate lyases, size-defined saturated oligosaccharides (M2 M5, G2 G5) were used as testing substrates. Pae-rAlgL and Avi-rAlgL degraded saturated poly-M oligosaccharides (M3-M5) but did not degrade M2 or G5 (Fig. 3C and D). When the saturated M5 sugars were degraded, the final products were mainly unsaturated UM2 (disaccharide), with a small amount of unsaturated UM3 (trisaccharide) and unsaturated UM4 (tetrasaccharide). UM2 is mainly produced when saturated M3 is degraded, while UM3 is mainly produced from M4. This indicates that the two enzymes Pae-rAlgL and Avi-rAlgL are M-specific alginate lyases that can react with the smallest saturated oligosaccharide substrate, $M 3$, and that the smallest product is saturated monosaccharide. In contrast, rAly- 6 degrades both $\mathrm{M}$ and $\mathrm{G}$ series oligosaccharide fragments (Fig. $3 A$ and $B$ ), although the product absorption intensity (area integral) of $M$ is significantly higher than that of $\mathrm{G}$ (approximately 5:1 10:1). For example, oligosaccharide yield produced by degradation of M5 is $8 \sim 10$-fold that of G5. M2 and G2 were not degraded. The products of degradation of M3/G3 are UM2/UG2 and saturated monosaccharides M/G, M4/G4 (UM2/UG2, UM3/UG3, M/G, and M2/G2), and M5/G5 (UM2/UG2, UM3/UG3, M/G and M2/G2). This fully showed that rAly-6 can degrade both $M / G$-rich oligosaccharide fragments with $M$ preference.

To exactly determine the substrate degradation orientation of Aly- 6 and two endolytic lyases, saturated/unsaturated alginate pentasaccharides (DP5) were labeled with 2-AB at the reducing end and further digested with enzymes in a time-course experiment. A gel filtration assay showed that the digestion of 2-AB-M5/2-AB-UDP5 by Aly-6 yielded a series of 2-AB-labeled oligosaccharide products with high molecular masses at the beginning of the reaction, and then, the larger products 2-AB-UM4/2-ABUDP4 and 2-AB-UM3/2-AB-UDP3 were gradually converted into the final product, 2-AB-UM2/2-AB-UDP2 (Fig. $4 A$ and $C$ ). In particular, the final product 2-AB-UM2 was formed in the initial stage of the reaction, and its yield gradually increased with reaction time. For the same experiment with 2-AB-G5, approximately $45 \%$ of the substrate was degraded to produce $2-A B-U G 2$ in equimolar amounts (Fig. 4B). The results indicated that the recombinant alginate lyase rAly-6 cleaved 2-AB-M5/2-AB-G5/2-AB-UDP5 as a monosaccharide-yielding exo-type enzyme; that is, it gradually cleaved one molecule of a saturated $M / G$ monosaccharide and two unsaturated monosaccharide units $(\Delta)$ from the nonreducing end of the substrate chain until one molecule of 2-AB-UM2/2-AB-UG2 remained.

As shown in Fig. 4D and E, 2-AB-M5 was produced by Pae-rAlgL or Avi-rAlgL, 2-AB-UM4 and 2-AB-UM3 were first produced, and finally 2-AB-UM3 and 2-AB-UM2 were the main products. However, when 2-AB-M4 was degraded, 2-AB-UM3 was the main final product (Fig. S6). In summary, this indicates that when PaerAlgL or Avi-rAlgL degrades 2-AB-M5, the main product of 2-AB-UM2 is not produced by continuous exocytosis, which is a variable substrate degradation mode with internal and external mode behavior.

To investigate the degradation patterns of the enzymes reacting against oligosaccharide substrates, each size-defined unsaturated oligosaccharide chain, i.e., the UDP2, UDP3, UDP4, and UDP5 fractions, was 
reacted with rAly- 6 using the same strategy as described previously. After further enzymatic reaction with rAly-6, the final digests of each size-defined oligosaccharide fraction were analyzed via gel filtration HPLC. The results showed that UDP3 and UDP2 were produced by degradation of UDP5 and UDP4, which contained only the $\triangle G$-terminus, and the degradation ratio of UDP3 was approximately $5 \%$, while that of UDP3 was $60 \%$ (mix of $\Delta \mathrm{M} / \Delta \mathrm{G}$-termini) (Fig. 5A). Furthermore, characteristic UDP2/M2/G2 fractions were degraded by rAly-6 (Fig. $5 B$ ), showing that the unsaturated disaccharide fragment $(\Delta M$ or $\Delta G$ ) was the smallest oligosaccharide substrate of rAly- 6 , wherein $\Delta M$ was more easily degraded than $\Delta G$, but neither could be completely degraded (Table. 2). Based on the above, the recombinant alginate lyase rAly6 is an M-preferred alginate lyase that can easily degrade alginate chains larger than trisaccharides or alginate chains containing $\Delta \mathrm{M}$ termini but cannot easily degrade alginate trisaccharide and disaccharide chains, particularly those containing $\triangle \mathrm{G}, \mathrm{GG}$ or $M M$ termini.

\subsection{Catalytic mechanism of rAly-6.}

Aly- 6 was determined to be composed of a6/a6 barrels and antiparallel $\beta$-chains as a sheet (Fig. S7A) with a crack-like catalytic cavity using Alg17c (PDB: 4NEI) as a template (Fig. S7B); this fold is significantly different from the barrel or jelly roll folds used by other PL family alginate lyases, with the extra peptide Gly ${ }^{224} \sim$ Ala $^{248}$ (Fig. 6A). After the extra peptide Gly ${ }^{224} \sim$ Ala $^{248}$ was truncated, there was little change in enzyme activity (Table. 3), indicating that the extra peptide was not a core essential structure and had a weak effect on the enzyme. Mutants H197A and W200A showed 46.09/144.53 U/mg activity on alginate (Table. 3), indicating that $\mathrm{HNH}^{197} \mathrm{STW}^{200}$ is the catalytic motif of Aly-6, which is a representative member of the PL17 subfamily. Moreover, H426A, Y269A, and N144A were approximately completely inactivated. According to similar literature reports, the sensitivity of this mutation inactivation is determined by the characteristics of Aly- 6 as an exolytic lyase.

Table 1

Activity of alginate lyases

\begin{tabular}{|llll|}
\hline & Alginate (U/mg) & M Block (U/mg) & G Block (U/mg) \\
\hline rAly6 & $726 \pm 2.2$ & $525 \pm 3.5$ & $196 \pm 2.9$ \\
\hline rTF-Aly6 & 692 & 547.9 & 183 \\
\hline rAly6-Lm & 34.6 & 25.1 & 5 \\
\hline rAly6-Hpm & 48 & 19.5 & 8 \\
\hline rAlgL-Pae & 2685 & 5704 & 144 \\
\hline rAlgL-Avi & 4219 & 8085 & 98 \\
\hline
\end{tabular}


Table 2

Oligosaccharides degraded by rAly- 6

\begin{tabular}{|lll|}
\hline Test Substrate & Product (s) & Degradation ratio (\%) \\
\hline$\Delta G$ & $\Delta$ & $5 \%$ \\
\hline$\Delta M$ & $\Delta$ & $90 \%$ \\
\hline$G G$ & -- & - \\
\hline$M M$ & -- & - \\
\hline$\Delta G X / \Delta M X$ & UDP2 & $60 \%$ \\
\hline$\Delta G X$ & UDP2 & $5 \%$ \\
\hline$\Delta G X X$ & UDP3, UDP2 & $95 \%$ \\
\hline$\Delta G X X X$ & UDP3, UDP2 & $98 \%$ \\
\hline
\end{tabular}

Table 3

Aly-6 mutant activity analysis

\begin{tabular}{|lll|}
\hline & mutants & Activity (U/mg) \\
\hline Metal ions & H426A & 0 \\
\hline Extra peptide & G224-A248 & 367 \\
\hline NNHSYW200 & W200A & 144.53 \\
\hline Active site residues & H197A & 46.09 \\
\cline { 2 - 3 } & Y231A & 566.4 \\
\cline { 2 - 3 } & Y269A & 9.709 \\
\cline { 2 - 3 } & N144A & 16.07 \\
\hline
\end{tabular}

\section{Discussion}

In this study, to elucidate and compare the core value of M-specific and M-preferred alginate lyases in alginate degradation, oligosaccharide preparation, and associated enzymatic mechanisms, we initially expressed, purified, and characterized two groups of enzymes: the first group, i.e., AlgL-Pae and AlgL-Avi, which include only one AlgL catalytic module, and the second group, i.e., Aly-6, which is composed of one AlgL-like module and one Hep_II_III-like module in sequence. As shown in Fig. 1 A, B, and C and indicated by the aforementioned sequence alignment, sequence similarities only lower than $30 \%$ were shared between the two studied protein groups. Furthermore, Aly- 6 of the Flammeovirga sp. strain MY04 was demonstrated to be an M-preferred bifunctional alginate lyase for the first time, whereas AlgL-Pae and AlgL-Avi were verified to be M-specific enzymes, as previously reported. Therefore, considering the 
substrate spectrum and enzyme activity comparisons of the truncated proteins, this study demonstrated that the AlgL-like module rather than the Hep_II_III-like module is the key catalytic element of Aly-6, although the two putative modules are integral in alginate degradation. Interestingly, the proteins of the two different groups showed similar biochemical characteristics and were similar affected by metal ions and chemical reagents in terms of their enzyme activities. Therefore, this study also indicated that the AlgL and AlgL-like modules play essential roles in determining the similar enzyme characteristics, although they differ greatly in sequence characteristics. Subsequently, the full-length Aly- 6 protein shares very low sequence identities with the PL15 and PL5 families of alginate lyases, containing only a Hep_II_III-like module or an AlgL-like module. Moreover, the whole Aly-6 protein shared very low protein sequence similarities (18\%) with heparinase II and heparinase III from Pedobacter heparinus.

Subsequently, we compared the catalytic characteristics of the two enzyme groups, particularly their alginate degradation patterns and oligosaccharide products. As mentioned above, the enzyme Aly- 6 is an M-preferred bifunctional exo-type alginate lyase, while the enzymes AlgL-Pae and AlgL-Avi are M-specific endo-type alginate lyases. Unsaturated disaccharides $(\Delta M$ or $\Delta G)$ are the smallest oligosaccharide substrates, and the $\Delta M$-terminal fractions are more easily degraded by Aly-6, so oligosaccharide products (UDP3-UDP6) obtained from incomplete degradation of alginate indicated that rAly- 6 is the first alginate lyase whose products contain only $\Delta \mathrm{G}$-terminal nonreducing ends for preparing a G-rich series of unsaturated oligosaccharide fragments with a $\Delta G$-terminus at the $n r$ end in incomplete degradation of alginate. Therefore, the structural features of oligosaccharide products are closely related to the enzymatic properties, such as the reported G-specific endolytic Aly5 and G-preferred bifunctional endolytic Aly1 and Aly2 lyases from Flammeovirga sp. MY04, in which the nrend succeeds from $\Delta G$ to $\triangle \mathrm{M}$ as the DP of oligosaccharide products increases. Interestingly, the M-specific endolytic lyases AlgLPae and AlgL-Avi derived from Pseudomonas aeruginosa and Azotobacter vinelandii have conserved structural features with analogous succession rules, from $\Delta \mathrm{M}$ to $\Delta \mathrm{G}$, which is the first reported oligosaccharide product characteristic of M-specific endolytic lyases. Furthermore, we confirmed that Aly6 gradually removes one molecule of a saturated $M / G$ monosaccharide or two molecules of an unsaturated monosaccharide from the nonreducing end in a monosaccharide exonuclease manner, and a 2-AB label at a saturated pentasaccharide inhibited the oligosaccharide degradation, especially that involving $\triangle M$ because of the steric hindrance caused by the 2-AB label, while AlgL-Pae and AlgL-Avi have a variable substrate degradation pattern whose key factors are the substrate molecule terminus type, degree of poly-Merization, and M/G ratio. Having a 2-AB label at the nrend had no significant effect.

In most cases, compared with endolytic enzymes, exolytic enzymes show very low enzymatic activity toward polysaccharides, possibly because polysaccharides are too large to efficiently bind to exolytic enzymes. The M-preferred monosaccharide-yielding exo-type alginate lyase Aly-6, with $726 \mathrm{U} / \mathrm{mg}$ activity, has significantly different properties from characterized alginate lyases, is stable in various tested physical and chemical environments and highly active, and has potential industrial applications. Therefore, Aly- 6 may be used for incomplete degradation of alginate to specifically prepare a series Gblock-rich unsaturated oligosaccharide fractions containing only $\Delta \mathrm{G}$-terminal or unsaturated trisaccharide fractions and unsaturated monosaccharide $\Delta$ by complete degradation. Furthermore, $\Delta$ has 
been deeply and unenzymatically converted into other products that provide an unsaturated monosaccharide carbon source for the growth of microorganisms or further bioconversion into biomass, e.g., ethanol. This is the key genetic basis for the ability of Flammeovirga sp. strain MY04 to grow with the sole carbon source of alginate.

Thus, we further focused on which remaining sites of the AlgL-like modules or of the Aly- 6 protein played essential roles in the catalysis of alginate. Notably, Aly- 6 possesses a different half-conserved "HNHSTW" catalytic motif, in which $\mathrm{His}^{197}$ is essential for stabilizing the negative charge on the carboxyl group in catalysis and $\mathrm{Ser}^{198}$ represents a characteristic active site residue of the Aly-6-containing novel subclass, while $\mathrm{Tyr}^{269}$ provides protons for the glycosidic bond.

In our study, we compared the suitability of a novel exolytic and two endolytic alginate lyases with mannuronate preference for direct preparation of oligosaccharides and determined the action modes and underlying catalytic mechanisms. These findings are very important for the direct preparation of specific sugar chains with designated sugar components and molecular sizes from alginate.

\section{Conclusions}

In addition to the previously reported G-specific endolytic alginate lyase Aly5 and M-preferred bifunctional alginate lyase Aly1, the M-preferred bifunctional Aly-6 of Flammeovirga sp. strain MY04 is a novel member of the PL17 superfamily. Notably, the catalytic modules of AlgL and AlgL-like proteins play essential roles in determining the similar enzyme characteristics although they are quite different in sequence characteristics. The identification of M-specific and M-preferred alginate lyases not only effectively supplements the study of alginate lyases but also provides three useful enzymes. Through studies of the enzymatic characteristics, substrate degradation patterns and oligosaccharide products, the structures of the final products were clearly elucidated, and the oligosaccharide products were determined by both substrate selectivity and oligosaccharide degradation mode.

\section{Abbreviations}

$\Delta$ : 4-Deoxy-L-erythro-5-hexoseulose uronic acid; DP: Degree of poly-Merization; G: Guluronate; M: Mannuronate; Poly-G: poly-Guluronate; Poly-M: poly-Mannuronate; SDS-PAGE: Sodium dodecyl sulfate polyacrylamide gel electrophoresis; HPLC: High-performance liquid chromatography; NMR: Nuclear magnetic resonance; PL family: Polysaccharise lyase family; UDP2: Unsaturated disaccharide; UDP3: Unsaturated trisaccharide; UPD4: Unsaturated tetrasaccharide; UPD5: Unsaturated pentasaccharide; UPD6: Unsaturated hexasaccharide; UPD7: Unsaturated heptaosaccharide; 2-AB: 2-aminobenzamide; UM: Unsaturated mannuronate; UG: Unsaturated guluronate.

\section{Declarations}

\section{Author agreements}


All authors agree to publish this article.

\section{Statement of informed consent}

No informed consent and human or animal rights applicable.

\section{Authors' contributions}

Lianghuan Zeng, Yuanyuan Cheng, and Junge Li designed the study under the guidance of Wenjun Han. Lianghuan Zeng and Wenjun Han drafted and corrected the manuscript. Lianghuan Zeng, Yuanyuan Cheng, and Junge Li, Dandan Wang and Jingyan Gu carried out the experiments, collected and analysed data. All authors read and approved the final manuscript.

\section{Funding and acknowledgements}

The work was supported by the Natural Science Foundation of Shandong Province (Grant No. ZR2019MD038), the Science and Technology Development Project of Shandong Province (No. 2018GHY115036), the Construction Project of Joint training Base for Postgraduate Education in Shandong Province (SDYJD18001), and Central Government Guide Local Science and Technology Development Funds (YDZX20203700002579).

\section{Availability of data and materials}

Not applicable.

\section{Ethics approval and consent to participate}

Not applicable.

\section{Consent for publication}

Not applicable.

\section{Competing interests}

The authors declare that they have no competing interests.

\section{References}

1. Meillisa A, Woo H.C, Chun B.S. (2015). Production of monosaccharides and bio-active compounds derived from marine polysaccharides using subcritical water hydrolysis. Food Chemistry, 171 (25308644), 70-77. https://doi.org/10.1016/j.foodchem.2014.08.097.

2. Gacesa P. (1988). Alginate. Carbohydrate poly-Mers, 8(3), 161-182, http://doi.org/10.1016/0144$\underline{8617}(\underline{88}) \underline{90001-x P e t e r}$. 
3. Maki H, Mori A, \& Fujiyama K. (1993). Cloning, sequence analysis and expression in Escherichia coli of a gene encoding an alginate lyase from Pseudomonas sp. OS-ALG-9. J Gen Microbiol, 139(5), 987993, https://doi.org/10.1099/00221287-139-5-987.

4. Haug A, Larsen B, \& SmidsrØd O. (1967). Studies on the sequence of uronic acid residues in alginic acid. Acta Chem Scand, 21, 691-704, https://doi.org/10.3891/acta.chem.scand.21-0691.

5. Papageorgiou S K, Katsaros F K, \& Kouvelos E P. (2006). Heavy metal sorption by calcium alginate beads from Laminaria digitata. Journal of Hazardous Materials, 137(3), 1765-1772, https://doi.org/10.1016/j.jhazmat.2006.05.017.

6. Ensor S A, Sofos J N, \& Schmidt G R. (1990). Optimization of algin/calcium binder in restructured beef. Journal of Muscle Foods, 1(3), 197-206, https://doi.org/10.1111/j.1745-4573.1990.tb00364.x.

7. Raybaudi-Massilia R M, Mosqueda-Melgar J, \& Martin-Belloso O. (2008). Edible alginate-based coating as carrier of antimicrobials to improve shelf-life and safety of fresh-cut melon. International journal of food microbiology, 121(3), 313-327, https://doi.org/10.1016/j.jjfoodmicro.2007.11.010.

8. Sen F, Uzunsoy I, \& Basturk E. (2017). Antimicrobial agent-free hybrid cationic starch/sodium alginate polyelectrolyte films for food packaging materials. Carbohydrate poly-Mers, 170, 264-270, https://doi.org/10.1016/j.carbpol.2017.04.079.

9. Narayanan K B, Han S S. (2017). Dual-crosslinked poly (vinyl alcohol)/sodium alginate/silver nanocomposite beads-A promising antimicrobial material. Food chemistry, 234, 103-110, https://doi.org/10.1016/j.foodchem.2017.04.173.

10. Guo W, Feng J, \& Geng W. (2012). Augmented production of alginate oligosahhcairdes by the Pseudomonas mendocina NK-01 mutant. Carbohydrate research, 352, 109-116, https://doi.org/10.1016/j.carres.2012.02.024.

11. Li S, He N, \& Wan L. (2019). Efficiently Anti-Obesity Effects of Unsaturated Alginate Oligosaccharides (UAOS) in High-Fat Diet (HFD)-Fed Mice. Mar. Drugs, 17(9), 540, https://doi.org/10.3390/md17090540.

12. Fan S, Chen X, \& Dai Z. (2019). Biological Activity of Alginate Oligosaccharides and Its Application in Food. Hans Journal of Agricultural Sciences, 9(3), 195-199, https://doi.org/10.12677/HJAS.2019.93029.

13. Zhou R, Shi X, \& Gao Y. (2015). Anti-inflammatory Activity of Guluronate Oligosaccharides Obtained by Oxidative Degradation from Alginate in Lipopolysaccharide-Activated Murine Macrophage RAW 264.7 Cells. Journal of Agricultural and Food Chemistry, 63(1), 160-168, https://doi.org/10.1021/jf503548a.

14. Hu J, Geng M, \& Li J. (2004). Acidic oligosaccharide sugar chain, a marine-derived acidic oligosaccharide, inhibits the cytotoxicity and aggregation of amyloid beta protein. Journal of pharmacological sciences, 95(2), 248-255, https://doi.org/10.1254/jphs.FPJ04004X.

15. Hu T, Li C, \& Zhao X. (2013). Preparation and characterization of guluronic acid oligosaccharides degraded by a rapid microwave irradiation method. Carbohydrate research, 373, 53-58, https://dx.doi.org/10.1016/j.carres.2013.03.014. 
16. Aida T M, Yamagata T, \& Watanabe M. (2010). Depoly-Merization of sodium alginate under hydrothermal conditions. Carbohydrate Poly-Mers, 80(1), 296-302, https://doi.org/10.1016/j.carbpol.2009.11.032.

17. Woods R J, Pikaev A K. (1994). Applied radiation chemistry: radiation processing. John Wiley \& Sons, ISBN 0-471-54452-3, (pp. 535). E-Publishing Inc. https://doi.org/10.1016/0969-8043(94)90180-5.

18. Chandia NP, Matsuhiro B, \& Vásquez A E. (2001). Alginic acids in Lessonia trabeculata: characterization by formic acid hydrolysis and FT-IR spectroscopy. Carbohydrate Poly-Mers, 46(1), 81-87, https://doi.org/10.1016/S0144-8617(00)00286-1.

19. Nagasawa N, Mitomo H, \& Yoshii F. (2000). Radiation-induced degradation of sodium alginate. PolyMer Degradation and Stability, 69(3), 279-285, https://doi.org/10.1016/S0141-3910(0ㅡ)00070-7.

20. Shimokawa T, Yoshida S, \& Kusakabe I. (1997). Some properties and action mode of (1->4)-alpha-Lguluronan lyase from Enterobacter cloacae M-1. Carbohyd Res, 304(2), 125-132, https://doi.org/10.1016/S0008-6215(97)00230-9.

21. Rehm BHA. (1998). Alginate lyase from Pseudomonas aeruginosa CF1/M1 prefers the hexameric oligosaccharide as substrate. Fems Microbiol Lett, 165(1), 175-180, https://doi.org/10.1111/j.15746968.1998.tb13143x.

22. Wong T Y, Preston L A, \& Schiller N L. (2000). Alginate lyase: Review of major sources and enzyme characteristics, structure-function analysis, biological roles, and applications. Annu Rev of Microbiol, 54, 289-340, https://doi.org/10.1146/annurev.micro.54.1.289.

23. Nakada H I, Sweeny P C. (1967). Alginic acid degradation by eliminases from a balone hepatopancreas. J Bio Chem, 242(5), 845-851, https://doi.org/10.1016/S0021-9258(18) $\underline{16201-0}$.

24. Fujimura T, Kawai T, \& Kajiware T. (1995). Protoplast isolation in the marine brown alga Dictyopteris prolifera, (Dictyotales). Plant Cell Reports, 14(9), 571-574, https://doi.org/10.1007/BF00231940.

25. Preiss J, Ashwell G. (1962). Alginic acid metabolism in bacteria. I. Enzymatic formation of unsaturated oligosaccharides and 4-deoxy-L-erythro-5-hexoseulose uronic acid. J Biol Chem, 237, 309-316, https://doi.org/10.1016/S0021-9258(18)93921-9.

26. Lee S I, Choi S H, \& Lee E Y. (2012). Molecular cloning, purification, and characterization of a novel poly MG-specific alginate lyase responsible for alginate MG block degradation in Stenotrophomas maltopholia KJ-2. Applied microbiology and biotechnology, 95(6), 1643-1653, https://doi.org/10.1007/s00253-012-4266-y.

27. Han W, Gu J, \& Cheng Y. (2016). Novel alginate lyase (Aly5) from a polysaccharide-degrading marine bacterium, Flammeovirga sp. strain MY04: effects of module truncation on biochemical characteristics, alginate degradation patterns, and oligosaccharide-yielding properties. Applied Environmental Microbiology, 82(1), 364-374, https://doi.org/10.1128/AEM.03022-15.

28. Cheng Y, Wang D, \& Gu J. (2017). Biochemical characteristics and variable alginate-degrading modes of a novel bifunctional endolytic alginate lyase. Applied Environmental Microbiology, 83(23), Article e01608-17, https://doi.org/10.1128/AEM.01608-17. 
29. Peng C, Wang Q, \& Lu D. (2018). A novel bifunctional endolytic alginate lyase with variable action modes and versatile monosaccharide-yielding properties. Frontiers in Microbiology, 9, Article 167. https://doi.org/10.3389/fmicb.2018.00167.

30. Ravanal M C, Pezoa-Conte R, \& von Schoultz S. (2016). Comparison of different types of pretreatment and enzymatic saccharification of Macrocystis pyrifera for the production of biofuel. Algal research, 13, 141-147, https://doi.org/10.1016/j.algal.2015.11.023.

31. Davidson I W, Sutherland I W, \& Lawson C J. (1977). Localisation of O-acetyl groups in bacterial alginate. Microbiology, 198, 603-606, https://doi.org/10.1.1.606.4426.

32. Gorin P A J, Spencer J F T. (1966). Exocellular alginate acid from Azotobacter vinelandii. Can J Chem, 44, 93-998, https://doi.org/10.1139/v66-147.

33. Linker A, Jones R S. (1964). A polysaccharide resembling alginic acid from a Pseudomonas microorganism. Nature, 204, 187-188, https://doi.org/10.1038/204187a0.

34. Han W, Gu J, \& Yan Q. (2012). A polysaccharide-degrading marine bacterium Flammeovirga sp. MY04 and its extracellular agarase system. Journal of Ocean University of China, 11(3), 375-382, https://doi.org/10.1007/s11802-012-1929-3.

35. Hall T A. (1999). BioEdit: a user-friendly biological sequence alignment editor and analysis program for Windows 95/98/NT. Nucl Acids Symp Ser. 41(41), 95-98, https://doi.org/10.1021/bk-19990734.ch008.

36. Sambrook J, Russell DW. (2001). Molecular cloning: a laboratory manual, 3rd ed, p A8.40-8.47. Cold Spring Harbor Laboratory Press, Cold Spring Harbor, New York, NY.

37. Kinoshita A, Sugahara K. (1999). Microanalysis of glycosaminoglycan-derived oligosaccharides labeled with a fluorophore 2-aminobenzamide by high-performance liquid chromatography: application to disaccharide composition analysis and exosequencing of oligosaccharides. Anal Biochem. 269(2), 367-378, https://doi.org/10.1006/abio.1999.4027.

38. Thomas F, Lundqvist LCE, \& Jam M. (2013). Comparative characterization of two marine alginate lyases from Zobellia galactanivorans reveals distinct modes of action and exquisite adaptation to their natural substrate. J Biol Chem 288, 23021-23037. http://dx.doi.org/10.1074/jbc.M113.467217.

39. Jun Y, Peng C, \& Yan Z. (2019). The Characterization and Modification of a Novel Bifunctional and Robust Alginate Lyase Derived from Marinimicrobium sp. H1. Marine Drugs, 17(10), 545, https://doi.org/10.3390/md17100545.

40. Lu D, Zhang Q, Wang S. (2019). Biochemical characteristics and synergistic effect of two novel alginate lyases from Photobacterium sp. FC615. Biotechnol Biofuels, 12, Article, 260. https://doi.org/10.1186/s13068-019-1600-y.

\section{Figures}




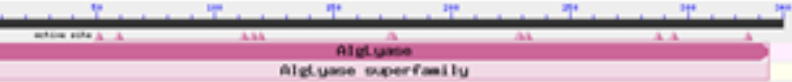

Avi.Alat.

La

C

Aly-6 Query seq.

Superfanillies

24

गक

$+2+5$

$44+2$

Alglyase superfanily

Now_II_III

D

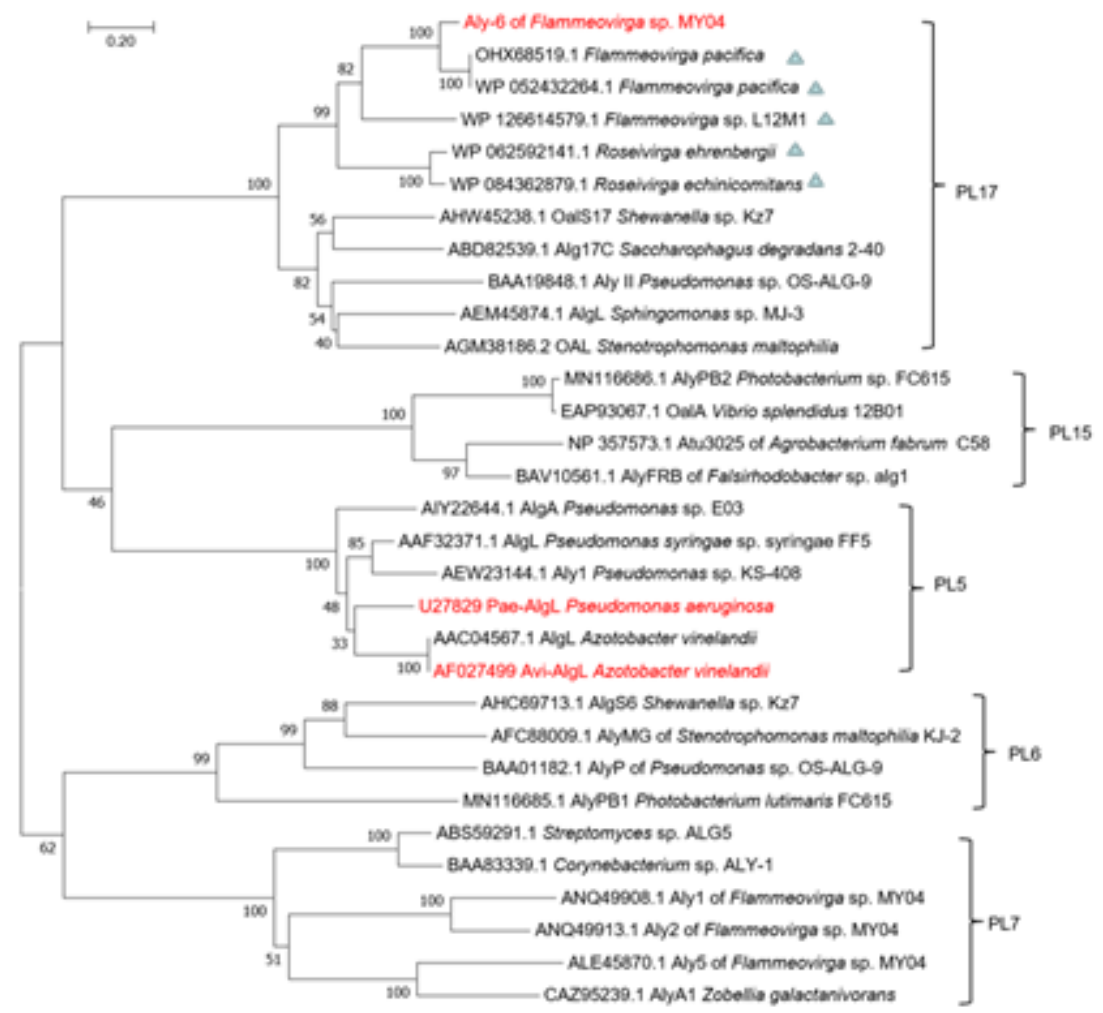

Figure 1

Sequence characteristics of alginate lyases Aly-6, Pae-AlgL, and Avi-AlgL. A, Module organization of PaeAlgL; B, module organization of Avi-AlgL; C, module organization of Aly-6; D, phylogenetic analysis of alginate lyases. The phylogenetic tree was constructed using MEGA version 7.2.5 software via the neighbor-joining algorithm, and associated taxa clustered together in a bootstrap test of 1000 replicates. 
A

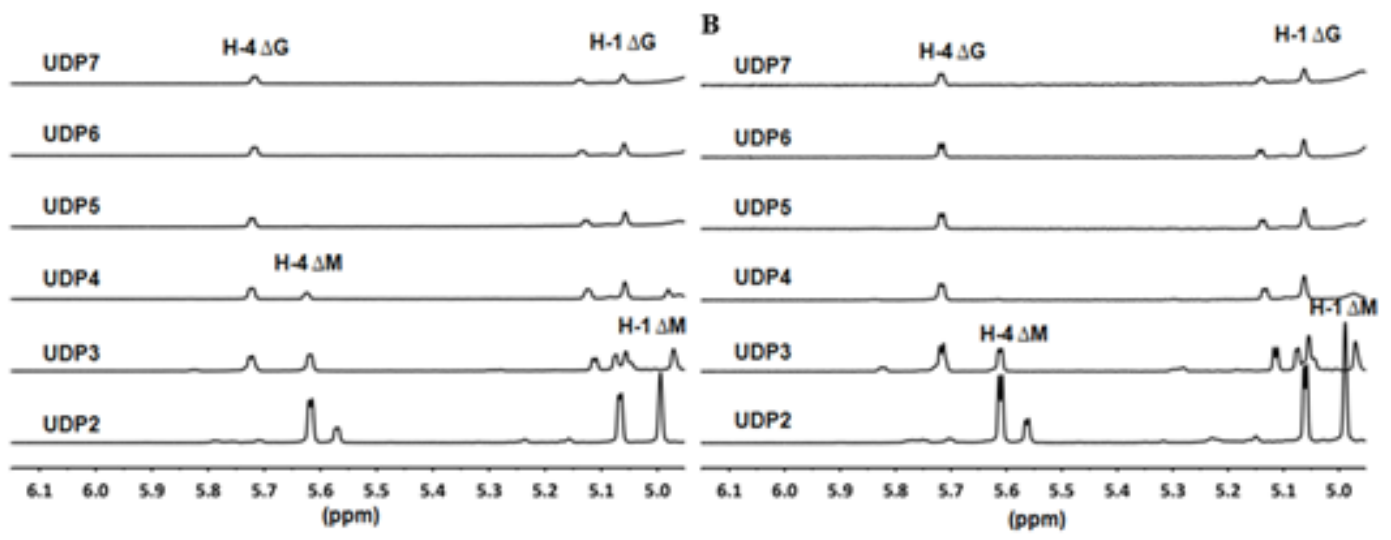

C
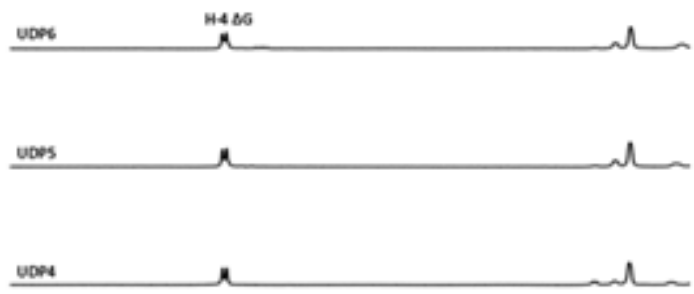

uops

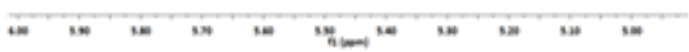

Figure 2

1H-NMR analyses of oligosaccharide products. A, 1 H-NMR (600 MHz) spectra of the main final products UDP2 UDP7 obtained from alginate digested by Pae-rAlgL. B, 1H-NMR $(600 \mathrm{MHz})$ spectra of the main final products UDP2 UDP7 obtained from alginate digested by Avi-rAlgL. C, 1H-NMR (600 MHz) spectra of the main final products UDP3 UDP6 obtained from alginate digested by rAly- 6 . 

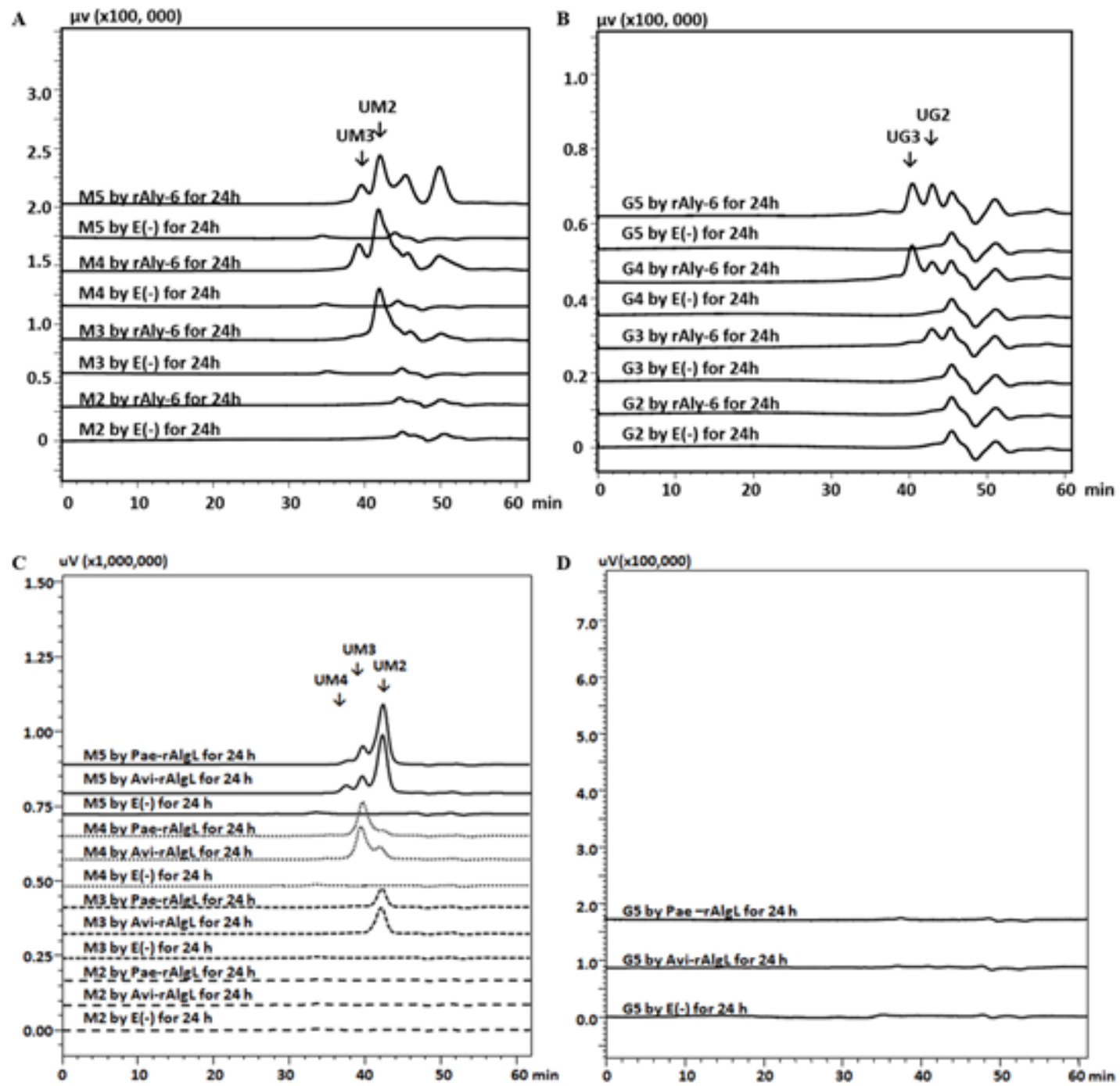

Figure 3

Substrate preferences of rAly-6, Pae-rAlgL, and Avi-rAlgL. Degradation of saturated oligosaccharides ( 20 $\mu \mathrm{g}$ ) by enzymes at their optimal temperatures for $12 \mathrm{~h}$. E (-), without enzyme (control group). HPLC analyses were performed using a Superdex peptide 10/300 GL column monitored at a wavelength of 235 $\mathrm{nm}$. G6, hexasaccharide of guluronate; $\mathrm{G} 5$, pentasaccharide of guluronate; M5, pentasaccharide of mannuronate. A, saturated M2 M5 degradation by rAly-6; B, saturated G2 G5 degradation by rAly-6; C, saturated M2 M5 degradation by Pae-rAlgL and Avi-rAlgL; D, saturated G5 degradation by Pae-rAlgL and Avi-rAlgL. 

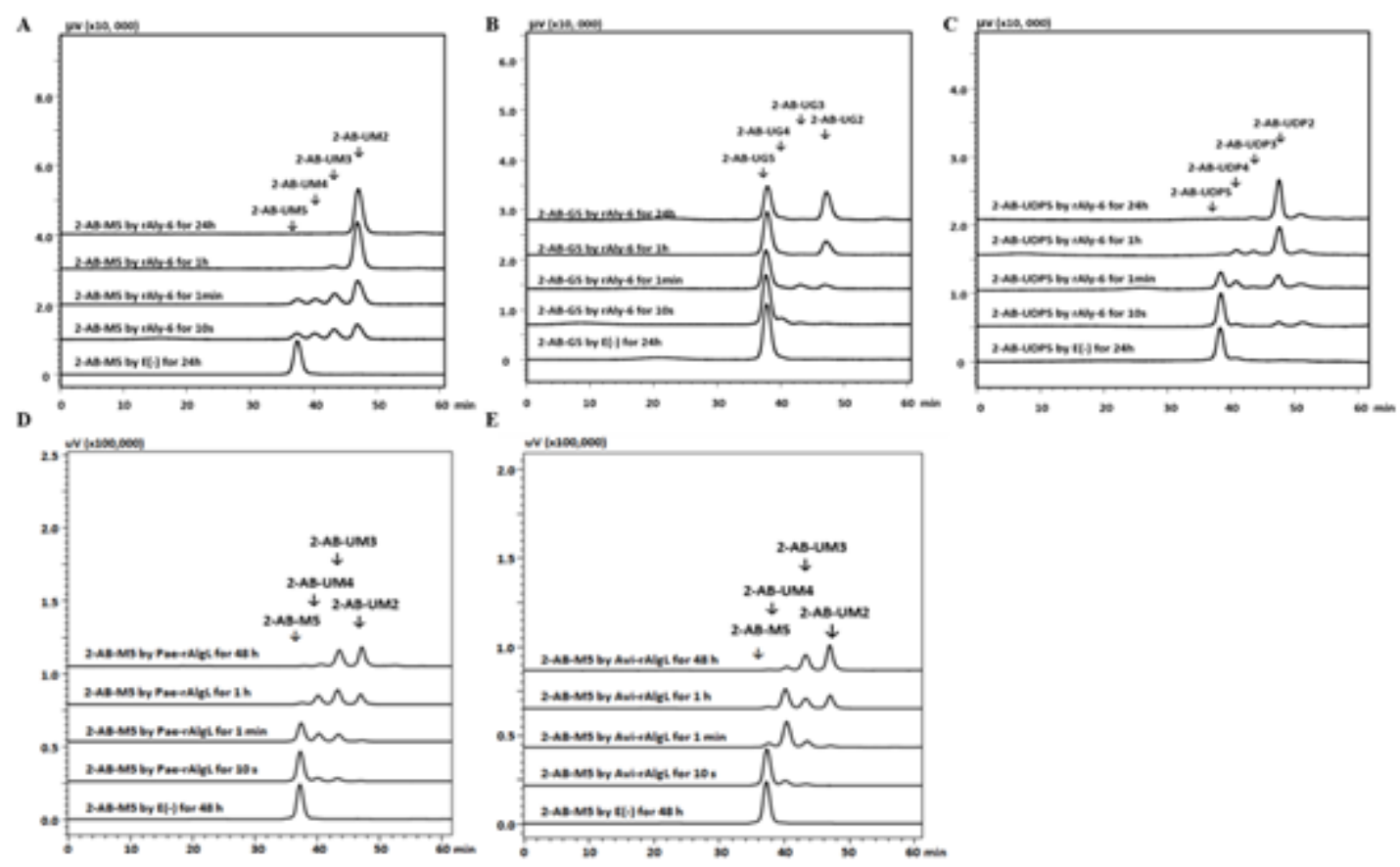

\section{Figure 4}

Analysis of the degradation orientation for rAly-6, Pae-rAlgL, and Avi-rAlgL. Time-course of 2-AB-labeled saturated or unsaturated alginate pentasaccharide degradation with enzymes under optimal conditions. E (-), without enzyme (control group). The resulting products were analyzed on a gel filtration Superdex peptide 10/300 GL column monitored using a fluorescent detector with an excitation wavelength of 330 $\mathrm{nm}$ and an emission wavelength of $420 \mathrm{~nm}$. A, 2-AB-M5 degradation by rAly-6; B, 2-AB-G5 degradation by rAly-6; C, 2-AB-UDP5 degradation by rAly-6; D, 2-AB-M5 degradation by Pae-rAlgL; E, 2-AB-G5 degradation by Avi-rAlgL.
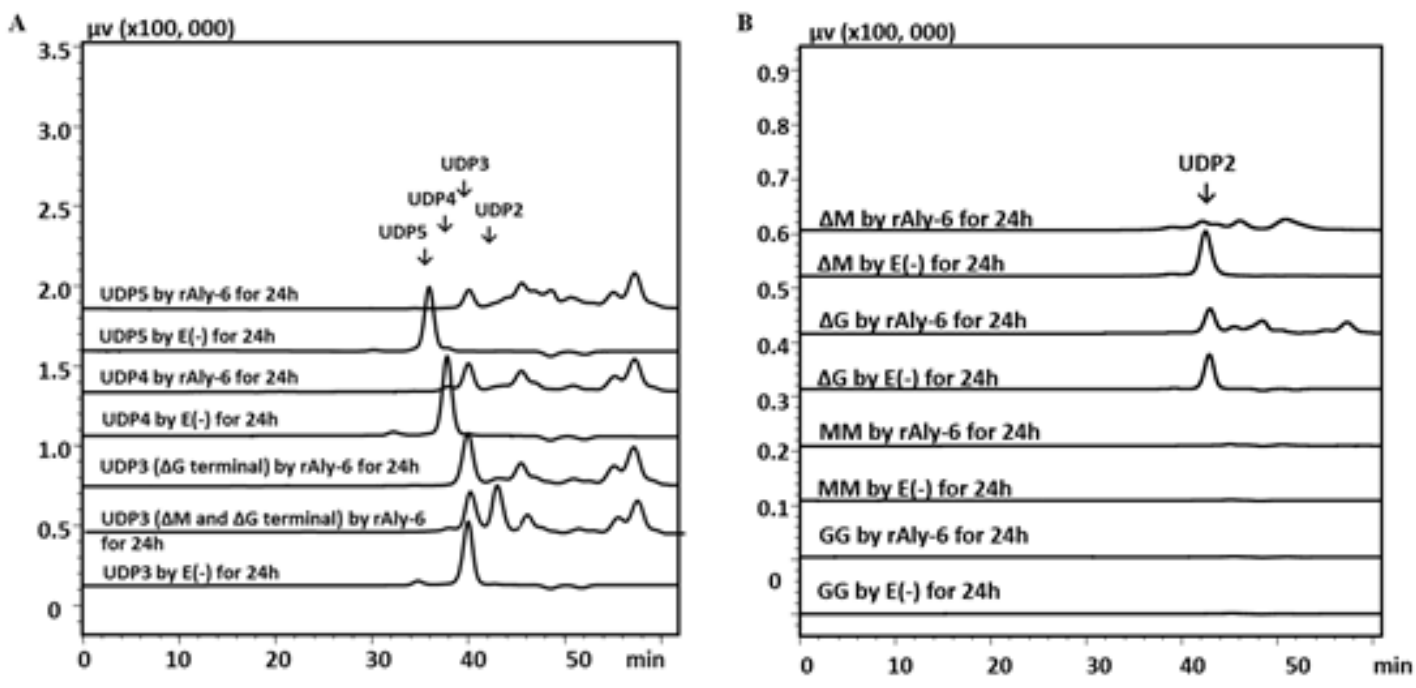

\section{Figure 5}

Analysis of oligosaccharide degradation by rAly-6. E (-), without enzyme (control group). The resulting products were analyzed by gel filtration using a Superdex peptide $10 / 300 \mathrm{GL}$ column monitored at 235 
nm. A, unsaturated oligosaccharides (UDP3-UDP5); B, disaccharide.
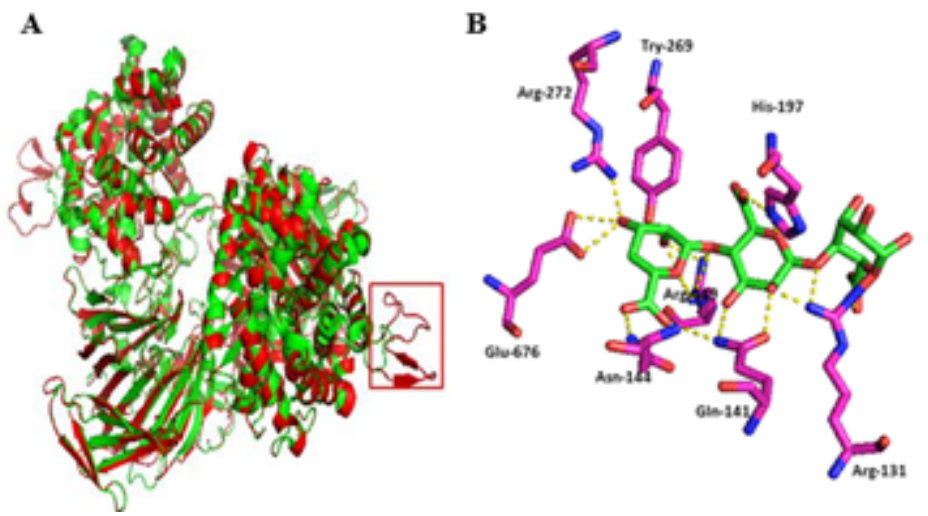

C

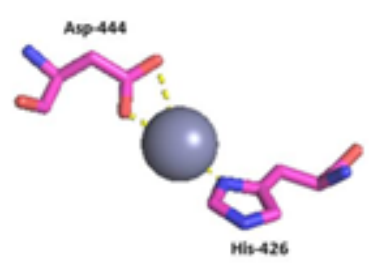

Figure 6

Active site residue prediction for Aly-6. The ligand BEM-MAV-LGU and Zn of the Y258A (PDB: 4OJZ) mutant of Alg17c were used to analyze the active site residues of Aly-6. BEM-MAV-LGU, unsaturated mannuronic acid, mannuronic acid, and guluronic acid. A, Structural comparison of Aly-6 (red) and Alg17c (green) and the extra peptide segment (red box); B, oligosaccharide ligand within $4 \AA$; C, metal ions (Zn) within $4 \AA$.

\section{Supplementary Files}

This is a list of supplementary files associated with this preprint. Click to download.

- SupplementaryMaterial.docx 